\title{
PNEUMOCONIOSIS IN BOILER SCALERS
}

\author{
BY \\ H. E. HARDING and A. P. MASSIE \\ From the Departments of Pathology, Sheffeld University, and Royal Infirmary, Hull
}

Every six months or so the majority of steamdriven ships spend a few days in docks having their boilers scaled and cleaned. In the larger docks there are men who are employed full time in this occupation, but elsewhere and in industry generally the cleaning is more often done as an occasional job. The total number of men engaged in the work full time is not large, but the occupation is a very dusty one and carries a definite risk of pneumoconiosis. Some details of the processes involved were given by Harding, McRae Tod, and McLaughlin (1944). Working in very confined spaces the boiler scaler crawls along with a lamp and a hammer chipping off the scale as he goes; frequently the boiler is still very warm, and he works in a hot atmosphere. The considerable amount of dust comes from two sources : that produced by breaking off the scale deposited in the tubes from the water, and the flue dust in the fire tubes arising from the coal or other fuel. Although the boiler scale contains varying quantities of silica this is present mainly as silicate, and it seems likely that the flue dust is the more important since it may contain free silica from the coal. Cooke (1930) reported $26.4 \%$ of silica in a sample of flue dust, Harding and others (1944) $6.1 \%$, while in a sample taken recently in Hull we have found $10 \%$.

Since the original case described by Cooke (1930), there have been only three further reports of necropsy findings : Williams (1931), and Harding and others (1944 and 1947), but the clinical and radiological findings have been reported on a number of cases, notably by Dunner (1943), and Dunner and Hermon (1944). In this report we give an account of eight boiler scalers whose lungs we have examined in whole or in part.

Case 1.-C. M., aged 60 years, had been employed as a marine boiler scaler for 44 years. He first attended his doctor in 1929 with " chronic bronchitis", and not again until 1946 when he was treated for six months for the same complaint. During this latter period he was referred to the tuberculosis centre where he was found to have a poor chest expansion and a diminished resonance over the left lung. The radiograph showed multiple small rounded nodules scattered diffusely throughout the left lung and in the upper and mid zones of the right lung. This nodulation was considered to be due to the second stage of silicosis. He again attended his doctor during three months in 1947 for treatment of his " bronchitis", and was advised to give up his occupation. He continued his work, however, until January, 1951, when he had an acute febrile respiratory illness from which he died.

A post-mortem examination was made on January 22, 1951, by one of us (A.P.M.). The body was wasted; the fingers showed slight clubbing. The mucous membranes of the trachea and bronchi were acutely inflamed, and a considerable amount of thick green mucopus was present in them. Old firm bilateral pleural adhesions were present.

The left lung was voluminous and showed a group of white fibrous plaques, approximately $1 \mathrm{~cm}$. in diameter on the pleural surface of its mid-lateral aspect. A solid hard mass $3 \mathrm{~cm}$. in diameter was palpable deep to these scars and lying in the upper lateral extremity of the lower lobe. Other tiny nodules were palpable deep to the pleura and scattered throughout the lung. On section the lung showed a heavy, diffuse, jet black pigmentation, and tarry black fluid exuded from the cut surface. Glistening black nodules 1 to $2 \mathrm{~mm}$. in diameter, rounded or stellate, were scattered fairly uniformly throughout the lung and gave a gritty sensation to the knife. The majority of these nodules were surrounded by groups of small cysts 1 to $3 \mathrm{~mm}$. in diameter giving the classical picture of "focal emphysema". A few larger cysts formed from coalescence measured up to $6 \mathrm{~mm}$. in diameter. The large solid pigmented mass had broken down in its central portion to produce a cavity $13 \times 7$ $\times 7 \mathrm{~mm}$.

The right lung was not quite as heavily pigmented as the left but a similar nodulation with focal emphysema was present throughout : it was more oedematous, and the lower lobe was partially consolidated by pneumonia, thick pus oozing from the terminal bronchioles. The hilar glands on both sides were enlarged, the left group more than the right, and all showed a heavy, diffuse, black pigmentation.

Slight atheromatous changes were present in the aorta and coronary vessels but the heart muscle and valves 


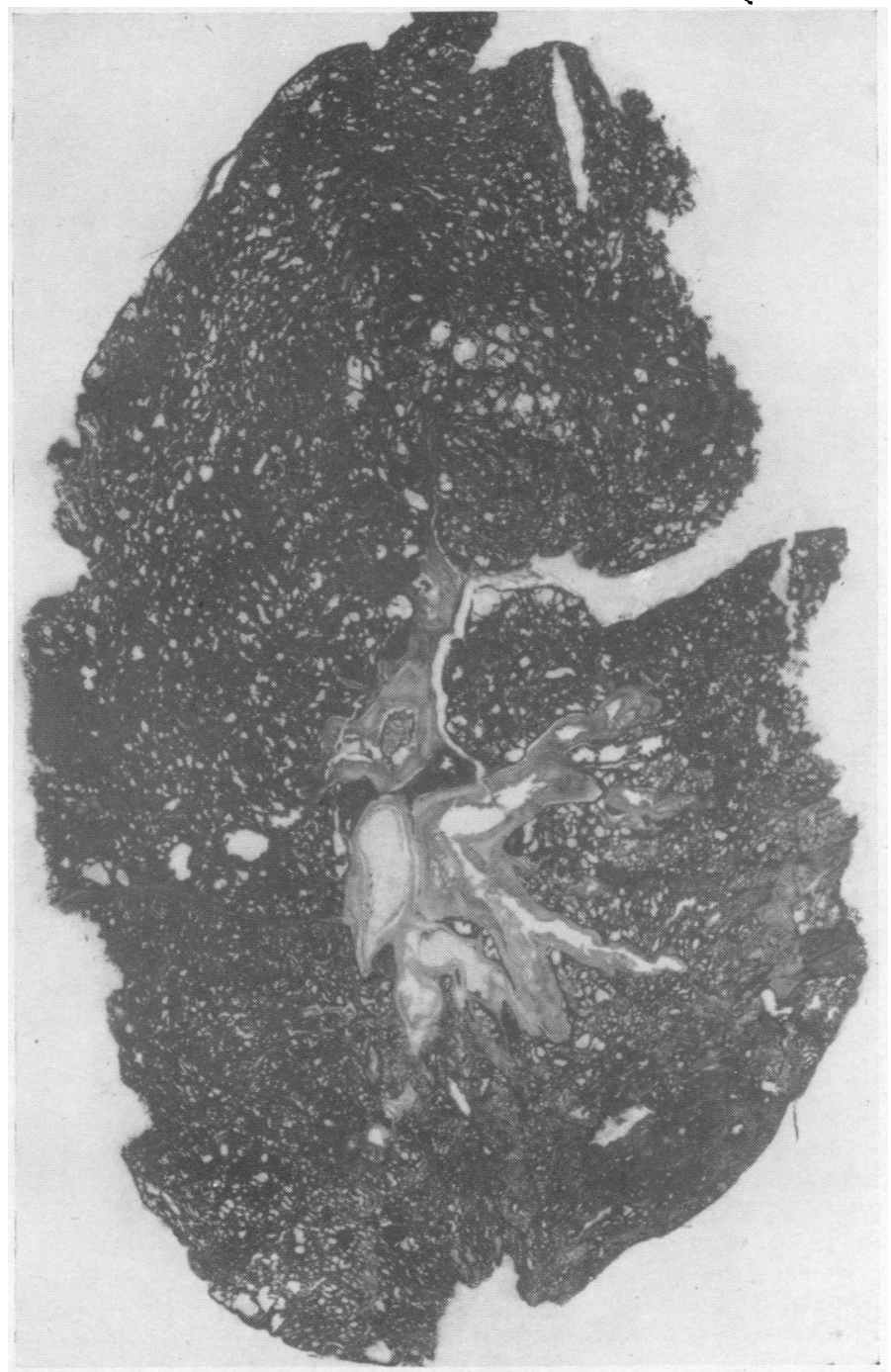

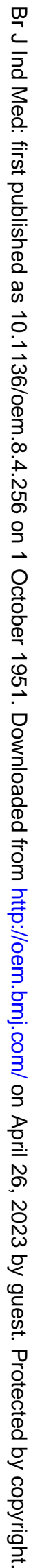
focal emphysema, pigmented nodulation.

FIG. 2,-Pigmented nodule in Case 1 with radial fibrosis : focal
emphysema. Haematoxylin and eosin. $\times 24$.

FIG. 2,-Pigmented nodule in Case 1 with radial fibro
emphysema. Haematoxylin and eosin. $\times 24$.

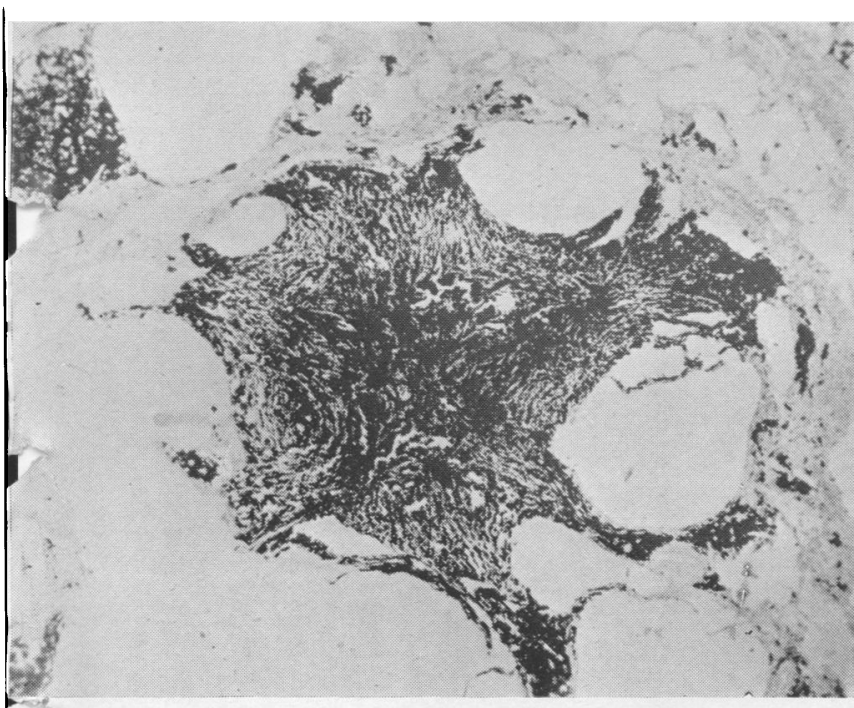

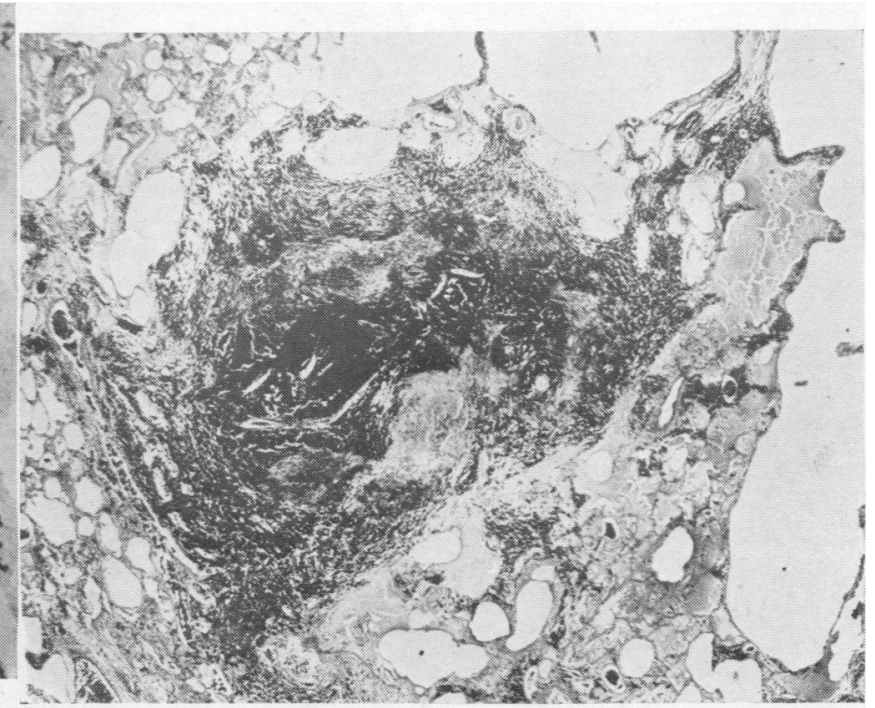

FIG. 3.-Early diffuse fibrosis in Case 1: focal emphysema.

Haematoxylin and eosin $\times 12$. 
showed no marked abnormality apart from some hypertrophy of the right ventricle. The liver showed some passive venous congestion but all the other organs appeared to be normal.

Death was attributed to acute tracheo-bronchitis and bronchopneumonia accelerated by pneumoconiosis.

After fixation in formalin the lungs had a blue-black mottled pleura with a pattern of white lines. The cut surface of the lungs (Fig. 1) showed fairly marked focal emphysema and a diffuse, black, fine nodulation much of which was palpable.

Histological examination (Figs. 2, 3) showed small numbers of dust cells in alveoli and accumulations of black pigment in the perivascular, peribronchial, interlobular and subpleural lymphatics. Most of the pigment was, however, in larger nodular masses distributed fairly evenly throughout the lung. These had a roughly stellate outline and were bounded by emphysematous spaces that were separated by the projecting spinous processes of the nodule. Collagenous fibrosis was present in the nodules and in the perivascular and other aggregates. It was linear or radial and not whorled. Fibrosis was more prominent in the area of massive consolidation in the left lower lobe, the central portion of which had undergone colliquative necrosis. Much pigment and a moderate amount of linear fibrosis were present in hilar lymph nodes. No evidence of tuberculosis was seen.

Case 2.-G.C., aged 61 years, was employed as a marine boiler scaler by the same firm as Case 1 continuously for 30 years, beginning when a youth. During the last five years of this period he visited his doctor frequently, complaining of a productive cough and shortness of breath. His symptoms progressed until he was forced to give up his employment, and he subsequently received sick benefit and did no work for two and a half years. In 1942 he began work cleaning motor buses. This occupation he found sufficiently light and comparatively clean. When examined by the Mass Radiography Service in October, 1947, his general condition was found to be poor. Bronchial breath sounds were present throughout his chest and numerous moist râles were heard. The radiograph (Figs. 4, 5) showed " widespread reticulation that spared the apices ; both lobes of the diaphragm were flattened ": these appearances were interpreted as due to early pneumoconiosis. Another radiograph a year later was reported as showing generalized nodular appearances over the whole of the lower zones of both lungs and to a lesser extent in the right upper zone. The lung markings were almost entirely absent in the mid and lower zones, and there was obliteration of the right costophrenic angle. This combination of nodulation and absent lung markings was interpreted as indicating a fairly advanced stage of silicosis. He was referred to the tuberculosis officer for surveillance, but tubercle bacilli were not found in his sputum after many examinations. His general condition slowly deteriorated. He gradually lost weight, and died in January, 1951.

On January 15, 1951 a necropsy examination was made by one of us (A.P.M.). The body was emaciated. The mucous membranes of the trachea and bronchi showed chronic inflammation. Bilateral, old, firm pleural adhesions were present especially on the left side. The left lung showed a few white scars on its apical surface. It was rather voluminous and on section showed a heavy black pigmentation. Hard, tiny nodules that were just palpable were scattered fairly uniformly throughout the lung: these nodules were jet black and shiny and surrounded by small cystic cavities approximately 1 to $3 \mathrm{~mm}$. in diameter. These areas of focal emphysema were more obvious in the lower lobe. The right lung showed a picture similar to the left, but the pigmentation was not as heavy and diffuse so that the nodular aggregation was more obvious. The lower lobe of this lung showed acute bronchopneumonia with purulent exudate in the bronchioles. The hilar lymph nodes were enlarged, and evenly and darkly black. No evidence of tuberculosis was found. There were advanced atheromatous changes and calcification of the aorta and coronary arteries. The cusps of the aortic valve were calcified, and there was some hypertrophy of each ventricle. The other organs showed no gross abnormality apart from venous congestion of the liver and atherosclerotic scars in the cortex of the kidneys. Death was attributed to acute bronchopneumonia, accelerated by pneumoconiosis and arteriosclerosis.

After fixation in formalin the lungs were very similar to those of Case 1 but the changes were not quite as marked.

Histological examination (Figs. 6, 7, 8) showed very few dust cells in the alveoli, most of the pigment lying in accumulations in the perivascular lymphatics where there was slight but definite collagenous fibrosis. There were many irregularly shaped nodules with a linear or radial arrangement of collagen fibres enclosing aggregations of pigment-filled cells. (This type of reaction we propose to call " mixed dust fibrosis" ; this term is discussed later in the paper.) These nodules varied in size up to nearly $1 \mathrm{~cm}$.; round the majority of them there was well marked focal emphysema. Acute purulent bronchopneumonia was present in the right lower lobe. Much of the black pigment disappeared on incineration, but there was an appreciable residue of iron oxide : acid treated incinerated sections showed a fine dusting with silica in the nodules.

Case 3.-W.P., aged 64 years, had been a ship's boiler scaler all his working life, over 40 years. He cleaned mainly the Scottish marine type of boilers with the combustion chamber running through the boiler. He worked inside the boilers. For some five to six years before his death he suffered from " chest trouble ", and ceased work because of disability in 1946. He made no claim for compensation, and was therefore not seen by the Pneumoconiosis Medical Panel during life. He died in 1951 from congestive heart failure due to pneumoconiosis, emphysema, and chronic bronchitis.

After fixation in formalin the lungs had a blue-black pleura in which were non-palpable white lines and white plaques up to $2 \mathrm{~cm}$. in diameter. The cut surfaces were very black and had numerous hard black nodules that were round or stellate and mainly 1 to $2 \mathrm{~mm}$. diameter. 
FIG. 4.-Radiograph of Case 2 (reduced).
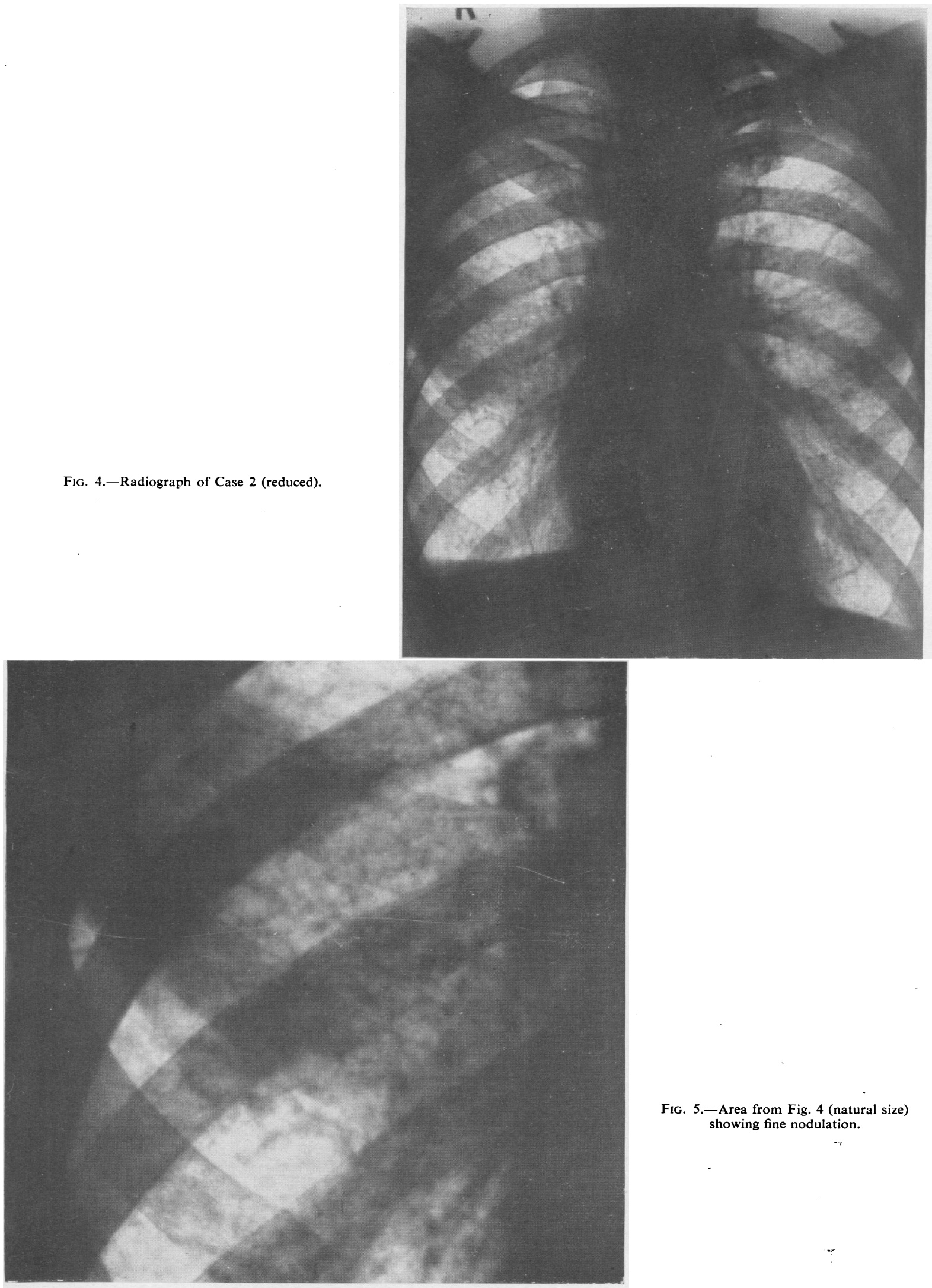

FIG. 5.-Area from Fig. 4 (natural size) showing fine nodulation. 

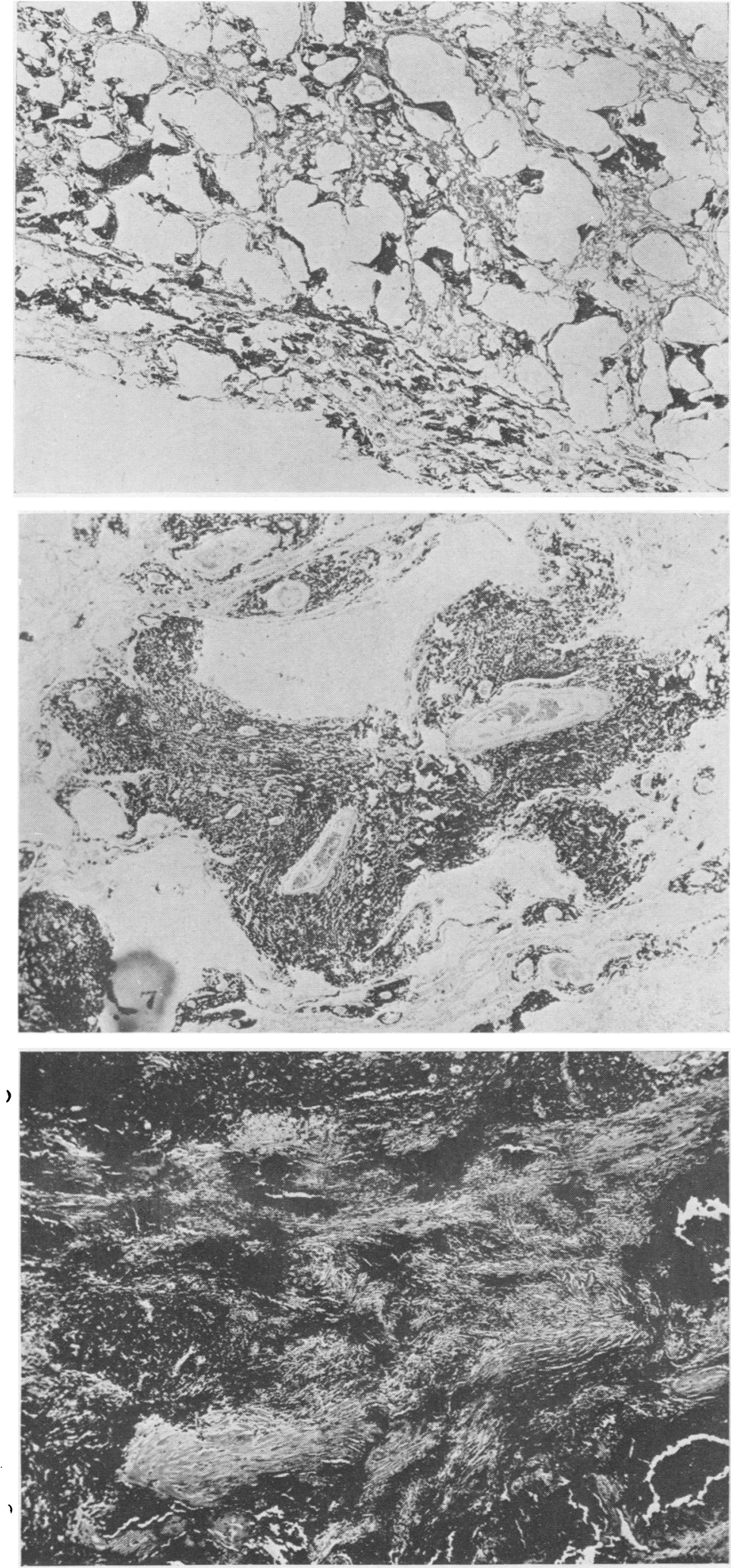

There was marked focal emphysema as well as marginal and apical bullous emphysema. The hilar lymph nodes were very large, black and firm.

Sections (Figs. 9, 10) were similar to those in the preceding cases but collagenous fibrosis was more conspicuous in the nodules and in places resembled early silicotic nodulation. No evidence of tuberculosis was found on naked eye or microscopic examination.

Case 4.-B.M., aged 64 years, had been a ship's boiler scaler in the Liverpool area practically all his working life and certainly for more than 30 years. From May, 1939, he worked only on and off, and in May, 1945, he gave up work entirely " because of his chest". He died in May, 1951, and a post-mortem examination was made by Dr. R. C. Nairn who gave the cause of death as "emphysema and chronic bronchitis ; anthracosis ; myocardial degeneration ".

The lungs, which had been fixed in formalin before we received them, were very torn and had evidently been grossly adherent to the chest wall. There was dense hyaline thickening of the pleura over the back and sides of both upper lobes. The lungs were very black and showed marked marginal and focal emphysema. Hard, glistening, black nodules of irregular shape up to $\frac{3}{4}$ in. in diameter were present in the apical and subapical regions of both lungs. Similar nodules were scattered throughout the lungs but were progressively smaller and fewer from the apices to the bases. Below the right apex was a ragged area that appeared to result from necrosis in an area of massive fibrosis, but might have been due to tearing at necropsy. The hilar nodes were not very large; they were very black but not very hard. Microscopically there was marked " mixed dust fibrosis" with moderately marked focal emphysema. The larger areas of fibrosis showed central necrosis. In these larger areas of fibrosis staining of the elastica revealed many solid arteries that were not readily distinguishable

FIG. 6.-Focal emphysema in Case 2 : mixed dust fibrosis. Haematoxylin and eosin $\times 4$.

FIG. 7.-Perivascular mixed dust fibrosis in Case 2. Haematoxylin and eosin $\times 12$.

FIG. 8.-Diffuse fibrosis in Case 2 of mixed dust type : pigmentation. Haematoxylin and eosin $\times 12$. 
with other stains. Nothing at all suggestive of tuberculosis was found, and it seems probable that the necrosis resulted from ischaemia.

Case 5.-J.W.L., aged 47 years, had been employed as a marine boiler scaler for 30 years. Except for a slight cough he had been well until February, 1946, when he complained of epigastric pains, anorexia, and flatulence. He was investigated in March, 1946, and a radiograph of his chest showed an opacity in the region of the right base, that was subsequently diagnosed as a bronchogenic carcinoma. His general condition gradually deteriorated with loss of weight and distressed breathing, and he died with multiple secondaries in January, 1947. The radiograph of his chest did not suggest pneumoconiosis.

A post-mortem examination on January 31, 1947, showed many secondary nodules in the skin of the abdomen and back, the largest the size of a walnut. The left lung showed a blue-black mottling of its pleura and several old adhesions. A generalized fine emphysema was present with some bullae at the anterior margin. Apart from the anterior margin the lung showed an almost uniform black pigmentation but some rather indefinite small nodules were palpable. The right lung in its upper portion showed a similar picture to the left, but nodules were more readily palpable. A carcinoma was present in the lower lobe extending half-way across it from the hilum. The remainder of the lower lobe appeared black with grey markings and felt hard, though not as hard as the areas of massive fibrosis in the lung of a miner. The pleura showed marked fibrous thickening over the whole lung. The hilar lymph nodes were moderately enlarged, black and very firm. The bronchial carcinoma had invaded the pericardium and heart muscle.
The right ventricle of the heart was hypertrophied. Generalized metastases were found in the abdominal viscera and in two ribs.

Histological examination of the lungs showed a good deal of black pigment in dust cells in the alveoli, in the alveolar walls, and in the subpleural lymphatics. Focal accumulations were present in the perivascular lymphatics and in some of these there was a slight reactive fibrosis around the pigment. A few emphysematous cysts were present, but "focal emphysema" was not a marked feature. There was rather more fibrosis in the right lower lobe with much included pigment, but the lung here appeared to be compressed by the growth rather than grossly fibrotic. The tumour had the structure of a poorly differentiated squamous cell carcinoma. The hilar lymph nodes showed a fairly well marked " mixed dust fibrosis", but no whorled nodules were present. Incinerated sections revealed only moderate amounts of iron and a slightly larger residue of silica than is found in sections from the lungs of men having no unusual exposure to dust.

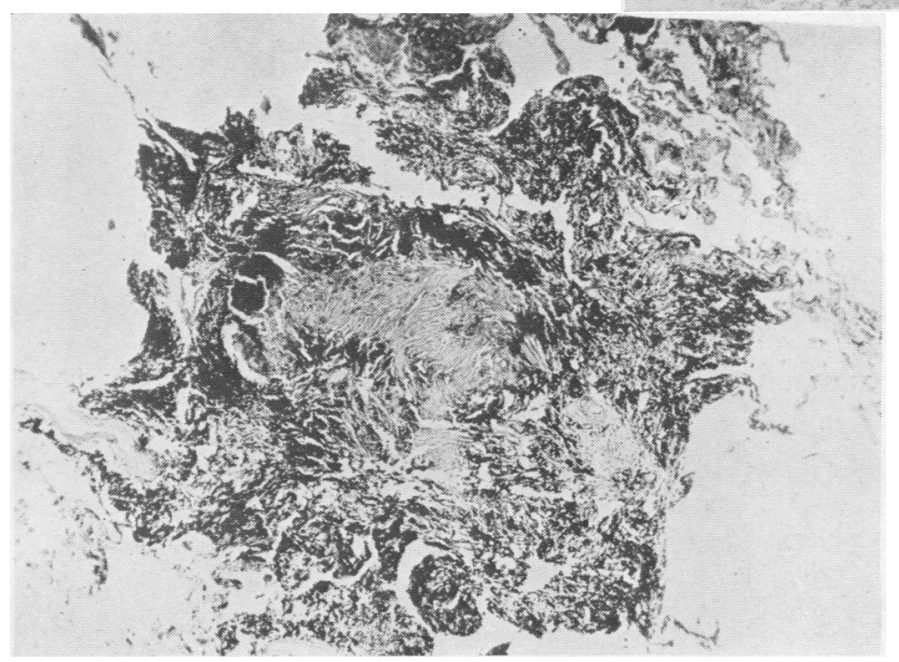

Fig. 9.-Mixed dust fibrosis in Case 3 : focal emphysema : oedema. Haematoxylin and eosin $\times 4$.

Fig. 10.-Nodule of mixed dust fibrosis in Case 3 with considerable collagen formation. Haematoxylin and eosin $\times 24$. 
Case 6. -W. McD., aged 60 years, had been in regular employment as a ship's boiler scaler for 25 years in the Lancashire area. His occupation before the age of 25 is unknown to us. In 1940 he had to give up work on account of disability from valvular disease of the heart. He was subsequently largely confined to bed, and died in June, 1949. After a post-mortem examination by Dr. Carraher, of Warrington, the cause of death was given as heart failure due to mitral stenosis.

The lungs after fixation in formalin showed slight thickening of the blue-black pleura in which were some white lines : a few old adhesions were present. Many small, black non-palpable nodules surrounded by fccal emphysema were present in the lungs. The hilar lymph nodes were moderately enlarged, very black, and moderately firm.

Histological examination showed well-marked mixed dust fibrosis with moderate focal emphysema: no silicotic nodules and no evidence of tuberculosis were found. The hilar lymph nodes were very pigmented, and showed marked linear fibrosis but no whorled nodules. Incinerated sections showed much iron in the nodules.

Case 7.-H. B., aged 57 years, had been employed for 17 years as a boiler scaler at a large industrial works in Lancashire. His other employment is unknown, but is believed not to have involved exposure to dust. $\mathrm{He}$ began to complain of dyspnoea in 1941, and died in March, 1948. After a post-mortem examination by Dr. A. McNeilly, of St. Helens, the cause of death was given as carcinoma of the left lung with secondary growths in both lungs.

The lungs had been fixed in formalin when seen by us. The left lung had evidently been densely adherent to the chest wall from which it had been torn and cut. A firm white tumour $1 \frac{1}{2}$ in. in diameter was present at and above the hilum and surrounding the main upper lobe bronchus: secondary nodules up to $2 \mathrm{~mm}$. in diameter were present throughout the lung which was not heavily pigmented and which contained no definitely fibrous nodules. The right lung showed a thickened pleura with denser scars near the apex and some old adhesions. Small nodules of new growth were scattered throughout. The lung was not very pigmented and no fibrous nodules were seen. The enlarged hilar lymph nodes were black, of normal consistency, and contained creamy nodules of tumour.

Histological examination showed an undifferentiated bronchial carcinoma in all sections, and considerable oedema of the lung. There was a moderate amount of black pigment around the pulmonary vessels, and a slight increase in reticulin fibrils around and among the aggregates of pigment, but no collagenous fibrosis. No evidence was found of tuberculosis nor was anything resembling silicotic nodulation seen.

Case 8.-J. F. was 48 when he died in 1949. From 1913 to 1919 he was employed as a doffer and warehouseman in a woollen mill ; from 1919 to 1941 boiler fireman on a Lancashire boiler in a woollen mill ; from 1941 to 1946 engine man in charge of the engine room at same firm. From 1919 to 1946 he also cleaned and scaled the boiler once a month and the economizer every two months. An analysis of the flue dust showed $33 \%$ total silica and $4 \%$ free silica.

He fell ill in August, 1946, and in September of that year was admitted to the General Infirmary at Leeds under Dr. H. H. Moll who made a diagnosis of silicotuberculosis. He was transferred to a sanatorium where he stayed until April, 1948. During this period his sputum consistently contained tubercle bacilli. Radiographs of his chest showed a large cavity in the region of the right apex with reticulation and a diffuse mottling and nodulation in the lung fields generally. The nodulation was most clearly defined in the last of the series. There was disagreement among the specialists consulted as to whether the appearances were due solely to tuberculosis or to silico-tuberculosis.

A post-mortem examination was made by Dr. H. H. Smith, of the Forensic Medicine Department, Leeds University, on April, 8 1949. "There were dense pleural adhesions covering the whole surfaces of both lungs. These were especially dense at the apices of both lungs and on the posterior surface of the right upper lobe. The lungs both felt nodular, the size of the nodules being up to a diameter of $\frac{1}{2} \mathrm{~mm}$. Especially in the apices of both lungs there were old and active areas of tuberculosis. Also scattered through the lung substance and in relation with the nodules the lungs presented an anthracotic silicotic appearance with a superadded caseous and purulent tuberculosis. Microscopical frozen sections of the lung showed numerous areas of anthra-

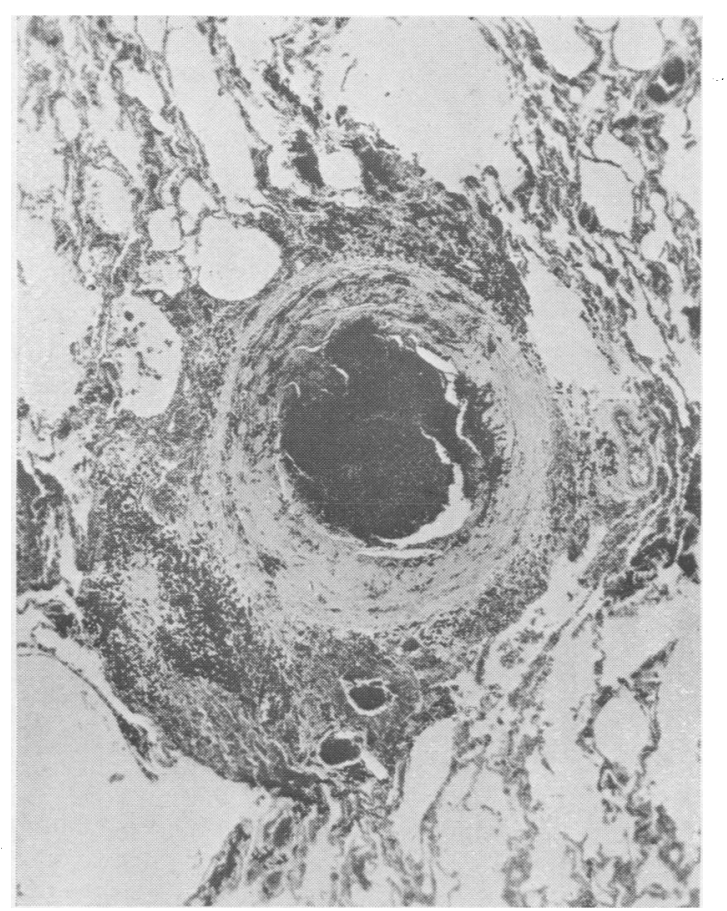

FIG. 11.-Nodule of healed tuberculosis with central calcified area in Case 8. Haematoxylin and eosin $\times 24$. 
cosis together with silicotic nodules surrounded by a dense fibrous capsule". The cause of death was given as "congestive heart failure following pulmonary tuberculosis and anthracotic silicosis ". On the strength of this necropsy report and the diagnosis of Dr. Moll, the widow was successful in her claim for compensation.

The only material available to us was a single paraffin block of lung. Sections from this showed several nodules about $2 \mathrm{~mm}$. in diameter with a thick, dense collagenous outer zone enclosing necrotic, partially calcified material (Fig. 11). In our opinion these nodules are healed tubercles, but there is insufficient evidence for us to decide that silica played no part in their production. The rest of the section showed only slight mixed dust fibrosis.

\section{Discussion}

The first four of these eight cases had pneumoconiosis of sufficient severity to produce disability and to be a factor in the cause of death. Cases 5 and 6 had definite pneumoconiosis but of lesser degree and probably playing little part in their deaths. Case 7 had a negligible amount of pneumoconiosis, while in Case 8 we consider the presence of pneumoconiosis unproven by the inadequate pathological examination although it was accepted by H.M. Coroner and by a court of law deciding compensation. These men had been employed as boiler scalers for $44,30,40,30+, 30,25,17$, and 27 years respectively, the first seven continuously, but the last only about once a month. The extent of the pneumoconiosis thus corresponded fairly well with the length of employment. In the absence of tuberculosis disability was not produced by less than 30 years' exposure.

Only one of the eight had tuberculosis (Case 8): Two of them (and one of the four cases previously reported) had bronchial carcinoma. These numbers are too small for any conclusion to be drawn from them. Three of them died of bronchopneumonia : in this connexion it may be relevant that Channell (1945) noticed a high incidence of upper respiratory infections in naval boiler scalers.

The type of pneumoconiosis that commonly occurs in boiler scalers appears essentially similar to that found in S. Wales coal workers (Gough, 1940, 1947). The deposition of dust is predominantly focal within small nodules distributed fairly evenly through the lungs mainly in relation to perivascular, peribronchial, interlobular, and subpleural lymphatics. In and around these deposits there is collagenous fibrosis not usually of severe degree and commonly linear or radial and not whorled. This type of reaction is often described as "dust reticulation", but we prefer the term " mixed dust fibrosis". It is in our experience a very common type of reaction found in many industries and trades where there is exposure to considerable quantities of dusts that vary considerably one from another, but all contain carbon and silica and usually iron oxide. In one sense it is a non-specific type of reaction (Heppleston, 1947), but we prefer to consider it as a form of modified silicosis until definite disproof of this view is given.

Although uncommon, whorled silicotic nodules may occur (Harding and others, 1944) just as they may occur in the lungs of a coal miner. Again as in other workers exposed to considerable quantities of mixed dusts, areas of massive fibrosis may occur as an extension of the process, and when they become large these areas may undergo necrosis in their central portions. Massive fibrosis was demonstrated radiologically by Dunner (1943), and was present in the first and fourth cases of this series. We are unconvinced by the argument that such lesions are invariably and necessarily due to added tuberculosis, and we found no evidence for such infection in our cases. On the other hand, we accept as a reasonable working hypothesis that local respiratory infections, tuberculous or other, play a part in their development.

Focal emphysema related to the nodules is a common feature of the pneumoconiosis of boiler scalers, and appears to increase with the length of employment. (We might here point out that the lungs in our cases were all cut before fixation, and were not first distended with formalin. Had they been treated by the methods of Gough, the focal emphysema would doubtless have been more conspicuous.) Focal emphysema of severe degree is most frequently seen in coal workers, but it occurs as a feature of the pneumoconiosis in many industries and trades where there is exposure to considerable quantities of mixed dust. We agree with Gough (1940) that it probably plays a large part in the production of dyspnoea and disability in these men. Williams (1944) suggested that it was produced by stenosis of respiratory bronchi as they pass through the coal foci, and Heppleston (1947) attributed it to the mechanical stress on the alveoli surrounding the nodules. We are inclined to believe that no single factor is responsible for its production but that it occurs only when considerable quantities of dust are present, and we have not yet seen it when the dust contained no free silica.

Although the number of men employed is small, we consider that there is now sufficient evidence for the inclusion of boiler scaling in the official schedule of occupations recognized as involving a risk of pneumoconiosis.

\section{Summary}

Pneumoconiosis in boiler scalers is essentially similar to that found in coal workers. In the 
absence of respiratory infection the condition becomes sufficiently severe to produce disability only after about 30 years' exposure.

We are indebted to Dr. J. Egan for Cases 3 and 4 ; to Dr. D. L. McRae Tod for details about Case 5 ; to Drs. C. L. Sutherland and F. N. R. Price for Cases 6 and 7 ; to Dr. W. D. Buchanan for drawing our attention to Case 8 and for other help; and to Professor C. J. Polson for the necropsy report and for sections of the lung of Case 8. The large section of the lungs of Case 1 was made by Professor J. Gough ; the photomicrographs were made by Mr. A. W. Collins, F.I.M.L.T.
Part of the expenses of this investigation were met by a grant to one of us from the Research Fund of Sheffield University.

\section{REFERENCES.}

Channell, G. D. (1945). J. roy. nav. med. Serv., 31, 146.

Cooke, W. E. (1930). Brit. med. J., 2, 816.

Dunner, L. (1943). Brit. J. Radiol., 16, 287.

-, and Hermon, R. (1944). Ibid., 17, 355

Gough, J. (1940). J. Path. Bact., 5i, 277.

-(1947). Occup. Med., 4, 86.

Harding, H. E., McRae Tod, D. L., and McLaughlin, A. I. G. (1944). British Journal of Industrial Medicine, 1, 247.

Heppleston, A. G. (1947). Ibid., 4, 100.

Williaston, A. G. (1947). J. Path. Bact., 59, 453.

Williams, E. (1944). Rep. Advisory Cttee. on Treatment and Rehabilitation of Miners in the Wales Region Suffering from Pneumoconiosis, p. 18. London.

Williams. H. J. (1931). 19th Ann. Rep., Welsh Nat. Memor. Assoc., 